\title{
Evaluating Factors for Predicting the Life Dissatisfaction of South Korean Elderly using Soft Margin Support Vector Machine based on Communication Frequency, Social Network Health Behavior and Depression
}

\author{
Haewon Byeon $^{1}$ \\ Department of Speech Language Pathology \\ Honam University, Gwangju, Republic of Korea
}

\author{
Seong-Tae Kim*2 \\ Department of Speech Language Pathology \\ Dongshin University, Naju, Republic of Korea
}

\begin{abstract}
Since health and the quality of life are caused not by a single factor but by the interaction of multiple factors, it is necessary to develop a model that can predict the quality of life using multiple risk factors rather than to identify individual risk factors. This study aimed to develop a model predicting the quality of life based on C-SVM using big data and provide baseline data for a successful old age. This study selected $\mathbf{2 , 4 2 0}$ elderly $(1,110$ men, 1,310 women) who were 65 years or older and completed the Seoul Statistics Survey. The quality of life satisfaction, a binary outcome variable (satisfied or dissatisfied), was evaluated based on a self-report questionnaire. This study performed a Gauss function among the SVM algorithms. To verify the predictive power of the developed model, this study compared the Gauss function with the linear algorithm, polynomial algorithm, and sigmoid algorithm. Additionally, CSVM and Nu-SVM were applied to four kernel algorithm types to create eight types, and prediction accuracies of the eight SVM types were estimated and compared. Among 2,420 subjects, 483 elderly $(19.9 \%)$ were not satisfied with their current lives. The final prediction accuracy of this SVM using 625 support vectors was $92.63 \%$. The results showed that the difference between $C$ SVM and Nu-SVM was negligible in the models for predicting the satisfaction of life in old age while the Gaussian kernel had the highest accuracy and the sigmoid kernel had the lowest accuracy. Based on the prediction model of this study, it is required to manage local communities systematically to enhance the quality of life in old age.
\end{abstract}

Keywords-C-SVM; communication frequency; life satisfaction; social network; quality of life

\section{INTRODUCTION}

Globally, the proportion of the elderly population is rapidly increasing due to economic growth, the advancement of medical technologies, and improved living standards. The aging speed of South Korea, in particular, is much faster than other countries in Europe, North America, Oceania, and Africa. As of 2018, the number of the elderly aged 65 or over was 7.38 million (14.3\% of the total population), indicating that one out of 7 people in the population is a senior citizen [1]. If this trend persists, the proportion of the elderly will reach $20.8 \%$ in 2026 and South Koreans will enter a post-aged society.

Since nuclearized families, decreased socioeconomic capacities, and chronic degenerative diseases such as dementia have increased, the quality of life in old age is lower than that of the young and middle-aged people [2]. The elderly are particularly vulnerable to diseases. Recent studies [3, 4, 5] reported that communication issues (e.g., dementia and aphasia) and swallowing problems as well as physical problems (e.g., degenerative joint diseases) adversely affected the quality of life in old age. The physical aging and chronic diseases that people experience in old age shrink the elderly psychologically and deprive them of positive emotions [6]. Additionally, psychological aging decreases mental and neurological functions such as sensation and intelligence and it also leads to emotional changes such as anxiety and depression [6]. Furthermore, the elderly often suffer from various difficulties such as aggravated health, disabilities, higher psychological alienation and loneliness, decreased economic ability, reduced the social role, and declined informal network due to diverse factors including physical aging, chronic diseases, and loss of spouse [7].

The satisfaction of life is a subjective evaluation regarding the satisfaction and perception of one's current life [8]. Moreover, this concept is widely used in gerontology and geriatrics studies [8]. An individual's quality of life indicates the well-being state containing the concepts of satisfaction, happiness, and positive emotions and includes physical factors, mental factors, social factors, and personal achievements [9]. In other words, the quality of life is an index that reflects not only physical factors but also mental factors such as health, occupational factors, social interaction, happiness, and satisfaction. The satisfaction of life is an important issue in gerontology because the satisfaction of life is not obtained by the general conditions of the elderly but formed by the interaction between the physical environment and the social environment that are directly experienced by them.

*Corresponding Authors. 
Previous studies $[10,11,12]$ have identified a variety of factors affecting the quality of life in old age such as sociodemographic factors (e.g., gender, age, income level, and educational level), marital status, and chronic diseases. Wada et al. [13] reported that the subjective satisfaction of life correlated with physical functions and health. Recent studies showed that social networks and the frequency of contacting people around them also influenced the quality of life in old age $[14,15]$. The elderly had higher satisfaction in life when they contacted family, relatives, friends, and neighbors more frequently and when they had various activities such as using senior citizen centers and community welfare centers [16].

Since health and the quality of life are caused not by a single factor but by the interaction of multiple factors, it is necessary to develop a model that can predict the quality of life using multiple risk factors rather than to identify individual risk factors [17]. Nevertheless, previous studies [18, 19] evaluating the risk factors affecting the quality of life in old age just aimed to explore individual risk factors using the generalized linear model. These studies [18, 19] mostly used logistic regression models to identify predictors. However, since regression models are used to predict the strength of the relationship between independent variables and dependent variables, this method is not appropriate to discover new predictors.

Recently, supervised learning algorithms such as the support vector machine (SVM) have been widely used in social science as a method of identifying complex factors associated with diseases and health problems [20]. Numerous studies [21, 22] have reported that the SVM has higher prediction power (accuracy) in classifying or predicting binary data than decision tree based machine learning or logistic models. Particularly, [23] showed that C-SVM, a transformation algorithm of the SVM, performs better because it makes the classification margin to classify two categories a serpentine nonlinear shape. This hyperparameter technique is drawing attention as a way to increase prediction power.

To date, it has not been tried to develop a prediction model reflecting health habits, subjective health, communication frequency, and social network, in addition to demographic factors, based on the supervised learning algorithm. This study aimed to develop a model predicting the quality of life based on C-SVM using big data and provide baseline data for a successful old age. Construction of our study is as follows. Section II explains database and analyzed variables and Section III defines C-SVM and explains the procedure of model development. Lastly, Section IV presents conclusion for future studies.

\section{METHODS AND MATERIALS}

\section{A. Target Subjects}

The data source of this study was the 2015 Seoul Statistics Survey. The Seoul Statistics Survey was conducted with the permission of the Statistics Korea in order to measure the welfare level of Seoul's resident population, track the changes in the welfare level by sector and year, and secure basic data for establishing the welfare policies of Seoul. The purposes of the Seoul Welfare Panel Survey were to (1) measure the welfare level of the resident population of Seoul and track the changes in welfare level by year; (2) estimate the demand for welfare services by identifying the size and status of the socially vulnerable class; (3) measure the effects of the program by evaluating the accessibility and satisfaction of citizens for the existing welfare service programs; (4) present baseline data for providing comprehensive welfare program through the above survey and measurement; and (5) pave the way to revitalize social science studies based on quantitative data by providing statistical data to social welfare researchers. The Seoul Statistics Survey contains items related to the quality of life such as income, consumption, savings, debt, assets, living conditions, health, housing, elderly support, child education, disability and rehabilitation, welfare services, cultural lives, and social participation. This study used computer assisted personal interviewing for surveying that trained investigators visited the homes of subjects and conducted face-to-face interviews using laptops. This study selected 2,420 adults (1,110 men, 1,310 women) who were 65 years or older and completed the Seoul Statistics Survey as the final subjects.

\section{B. Measurements of Variables}

The definitions of the variables measured in this study are presented in Table I. The quality of life satisfaction, a binary outcome variable (satisfied or dissatisfied), was evaluated based on a question, "Are you satisfied with your life?". Explanatory variables included gender, age (i.e., 65-74 years old and 75 years or older), the highest level of education (i.e., below elementary school, middle school, high school, and equal to or higher than collage graduation), monthly mean total household income (i.e., $<2$ million KRW, 2 million $\mathrm{KRW} \leqslant$ and $<4$ million $\mathrm{KRW}$, and 4 million $\mathrm{KRW} \leqslant$ ), marital status (i.e., living with a spouse, married but not living with a spouse, and not married), current employment status (i.e., employment and unemployment), drinking frequency (i.e., less than once a week and more than once), smoking (i.e., smoking and nonsmoking), walking per week (i.e., equal to or more than two days and less than one day), subjective health status (i.e., good, normal, and bad), depression (i.e., yes and no), disease or accident experience in the past two weeks (i.e., yes and no), the frequency of meeting a neighbor (i.e., less than once a month and more than twice a month), and frequency meeting a relative (i.e., less than once a month and more than twice a month). Depression was measured using the Short Form Geriatric Depression Scale (SGDS) [24]. SGDS is easy to test the depression of the elderly, does not take much time, and is highly valid [24]. For each question, 'Yes' was given 1 point, and 'No' was given 0 points. The total depression score ranged from 0 to 15 . The threshold for depression was 8 , and a higher score means more severe depression. The reliability of SGDS in this study was evaluated by Cronbach's $\alpha(.881)$. 
TABLE. I. THE DEFINITIONS OF THE VARIABLES MEASURED IN THIS STUDY

\begin{tabular}{|c|c|c|}
\hline Category & Factor & Measurement \\
\hline \multirow[t]{6}{*}{$\begin{array}{l}\text { Demographic } \\
\text { characteristics }\end{array}$} & Gender & Male, Female \\
\hline & Age & $65-74,75+$ \\
\hline & $\begin{array}{l}\text { Income (Monthly mean } \\
\text { total household income) }\end{array}$ & $\begin{array}{l}<2 \text { million KRW, } 2 \text { million } \\
\mathrm{KRW} \leq \text { and }<4 \text { million } \\
\mathrm{KRW} \text {, and } 4 \text { million } \\
\mathrm{KRW} \leq\end{array}$ \\
\hline & Marital status & $\begin{array}{l}\text { Not married, Married but } \\
\text { not living with a spouse, } \\
\text { Living with a spouse }\end{array}$ \\
\hline & Education level & $\begin{array}{l}\text { Below elementary school, } \\
\text { Middle school, High } \\
\text { school, Equal to or higher } \\
\text { than collage graduation }\end{array}$ \\
\hline & $\begin{array}{l}\text { Current employment } \\
\text { status }\end{array}$ & $\begin{array}{l}\text { Employment, } \\
\text { Unemployment }\end{array}$ \\
\hline \multirow[t]{3}{*}{ Health behavior } & Current Smoking & No, Yes \\
\hline & Drinking frequency & $\begin{array}{l}\text { Less than once a week, } \\
\text { More than once }\end{array}$ \\
\hline & Walking per week & $\begin{array}{l}\text { Less than one day, Equal to } \\
\text { or more than two days }\end{array}$ \\
\hline \multirow[t]{2}{*}{$\begin{array}{l}\text { Social Network / } \\
\text { Communication } \\
\text { Frequency }\end{array}$} & $\begin{array}{l}\text { Frequency of meeting a } \\
\text { neighbor }\end{array}$ & $\begin{array}{l}\text { More than twice a month, } \\
\text { Less than once a month }\end{array}$ \\
\hline & $\begin{array}{l}\text { Frequency meeting a } \\
\text { relative }\end{array}$ & $\begin{array}{l}\text { More than twice a month, } \\
\text { Less than once a month }\end{array}$ \\
\hline Health status & $\begin{array}{l}\text { Disease or accident } \\
\text { experience in the past } \\
\text { two weeks }\end{array}$ & No, Yes \\
\hline Depression & $\begin{array}{l}\text { Short Form Geriatric } \\
\text { Depression Scale(SGDS) }\end{array}$ & No, Yes \\
\hline Life satisfaction & $\begin{array}{l}\text { Subjective Life } \\
\text { Satisfaction }\end{array}$ & Satisfied, not satisfied \\
\hline
\end{tabular}

\section{ANALYSIS METHODS}

\section{A. Support Vector Machine}

The model for predicting the quality of life in old age was developed using the support vector machine (SVM). The SVM is a machine learning algorithm that finds the optimal decision boundary, linear separation, that divides hyperplane optimally by transforming the learning data to a higher dimension through non-linear mapping [25]. For example, $A=[a, d]$ and $\mathrm{B}=[\mathrm{b}, \mathrm{c}]$ have non-linearly separable characteristics in twodimension. When they are mapped to three-dimension, it has a linearly separable characteristic. Therefore, when an appropriate nonlinear mapping is used to a sufficiently large dimension, a dataset, which has two classes, can always be separated in the hyperplane. The SVM is very accurate because it can model the complex nonlinear decision-making domain, and it tends to have less over-fitting possibilities than other models, which is an advantage [25].

\section{B. C-SVM Algorithm}

The hyperplane of the SVM was used to classify linear forms. However, the use of kernel functions allows conducting nonlinear as well as the linear classification for a complex dataset (Fig. 1) [26]. Fig. 2 shows the transformed data (right) by mapping the actual data (left) to the feature space through a kernel function. The figure on the right reveals the process of deriving a linear hyperplane by conducting the SVM. C-SVM is often used as a criterion for classifying nonlinearities in a complex dataset (Fig. 3).

This study performed the radial basis function (a Gauss function) among the SVM algorithms. To verify the predictive power of the developed model, this study compared the Gauss function with the linear algorithm, polynomial algorithm, and sigmoid algorithm. Additionally, C-SVM and Nu-SVM were applied to four kernel algorithm types to create eight types, and prediction accuracies of the eight SVM types were estimated and compared. The analysis was conducted using $\mathrm{R}$ version 3.4.3.

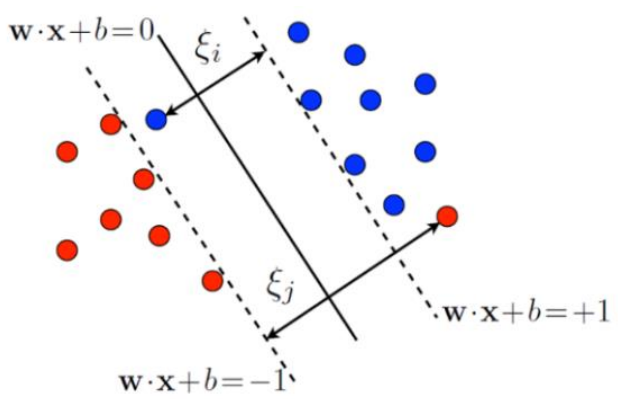

Fig. 1. The Concept of Kernel Functions [26].

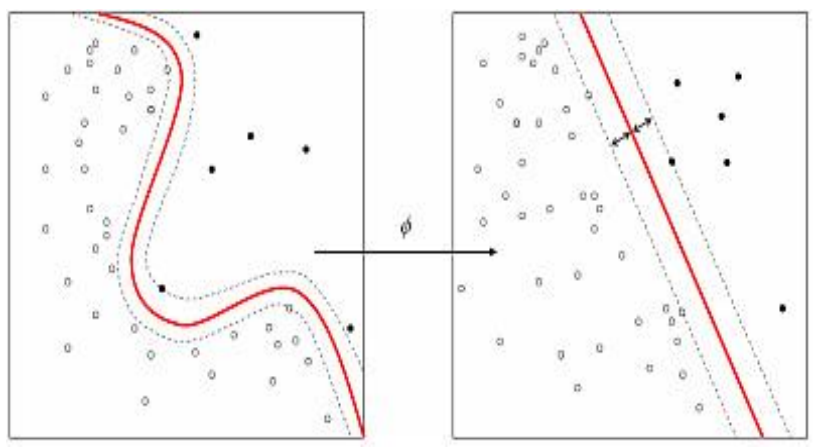

Fig. 2. The concept of soft-margin [26]
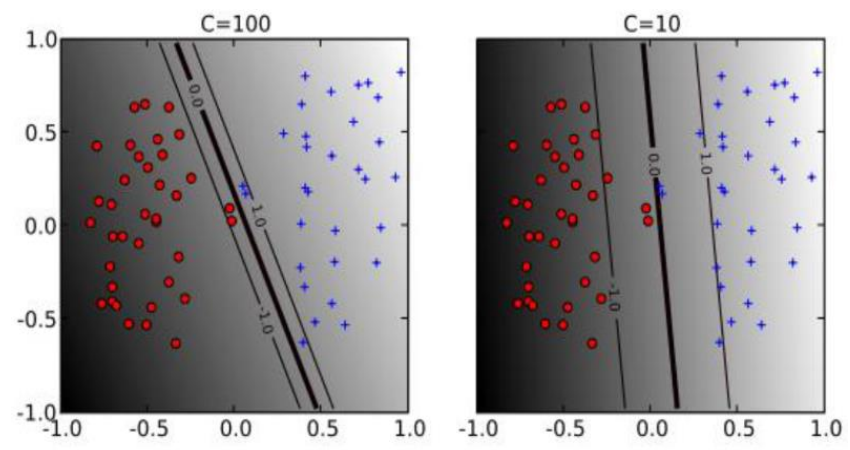

Fig. 3. Effect of Soft-margin [26] 


\section{RESUlts}

\section{A. General Characteristics of Subjects}

Among 2,420 subjects, 483 elderly (19.9\%) were not satisfied with their current lives (Table II). The results of chisquare test showed that age, gender, education level, economic activity, living with a spouse or not, subjective health status, walking practice per week, depression, illness and accident experience within the past two weeks, the frequency of meeting a neighbor, and the frequency of meeting a relative were significantly different between the elderly satisfied with their lives and those not satisfied with their lives $(\mathrm{p}<0.05)$. The ratio of life dissatisfaction were high when subjects were 75 years old or older $(37.5 \%)$, males $(23.1 \%)$, elementary school graduates or below $(26.1 \%)$, unemployed $(26.1 \%)$, separated from spouses $(32.3 \%)$, poor subjective health $(20.4 \%)$, senior citizens who walked one day or less per week on average (25.7\%), depression $(66.3 \%)$, senior citizens who experience a disease or an accident in the past two weeks (29.5\%), when the frequency of meeting a neighbor is less than once a month $(35.2 \%)$, when the frequency of meeting a relative is less than once a month $(37.2 \%)$.

\section{B. Predictors of Life Dissatisfaction based on C-SVM}

The function weights of the SVM based on the Gaussian kernel algorithm are presented in Table III. Although it is impossible to simply compare the magnitudes (priorities) of variables using the function weights of C-SVM, it is possible to determine whether the predictor is a preventative factor (positive relationship) or a risk factor (negative relationship). This C-SVM based model for predicting the quality of life in old age derived both preventive and risk factors. Since the objective of this study was to explore the main predictors of life dissatisfaction in old age, this study only evaluated factors affecting life dissatisfaction. It was found that the predictors of life dissatisfaction in old age were 75 years old or older, currently unemployed, household income equal to or below 4 million KRW, middle school graduate or below, male, poor subjective health, depression, experienced a disease or accident in the past two weeks, walk one day or less per week, and the frequency of meeting a relative or neighbor equal to or less than once a month. The final prediction accuracy of this SVM using 625 support vectors was $92.63 \%$.

\section{Ccuracy of Predicting the Satisfaction of Life in Old Age According to the Classification Algorithm of the SVM}

The accuracy of predicting the satisfaction of life according to the classification algorithm of the SVM is presented in Table IV. The model fitness of the SVM may vary depending on a kernel type. Therefore, this study compared the prediction accuracy of diverse algorithms (i.e., Gaussian, linear, polynomial, and sigmoid) to evaluate the prediction accuracies of models according to a kernel type. Moreover, this study examined two SVM types (C-SVM and Nu-SVM), so this study compared the prediction accuracies of eight different SVM types. The results showed that the difference between CSVM and Nu-SVM was negligible in the models for predicting the satisfaction of life in old age while the Gaussian kernel had the highest accuracy and the sigmoid kernel had the lowest accuracy.
TABLE. II. ChARACTERISTICS OF PARTICIPANTS BASED ON LIFE SATISFACTION, N (\%)

\begin{tabular}{|c|c|c|c|}
\hline \multirow[b]{2}{*}{ Variables } & \multicolumn{2}{|c|}{ life satisfaction } & \multirow[b]{2}{*}{$\mathrm{p}$} \\
\hline & $\begin{array}{l}\text { Satisfied } \\
(\mathrm{n}=1,937)\end{array}$ & $\begin{array}{l}\text { Not } \\
\text { satisfied } \\
(\mathrm{n}=480)\end{array}$ & \\
\hline Age & & & $<0.001$ \\
\hline $65-74$ & $1,333(75.3)$ & $438(24.7)$ & \\
\hline $75+$ & $404(62.5)$ & $242(37.5)$ & \\
\hline Gender & & & $<0.001$ \\
\hline Male & $854(76.9)$ & $256(23.1)$ & \\
\hline Female & $1,083(82.7)$ & $227(17.3)$ & \\
\hline Education & & & $<0.001$ \\
\hline $\begin{array}{l}\text { Elementary school graduation } \\
\text { and below }\end{array}$ & 675 (79.9) & $238(26.1)$ & \\
\hline Middle school graduation & $243(78.1)$ & $68(21.9)$ & \\
\hline High school graduation & $528(83.7)$ & $103(16.3)$ & \\
\hline College graduation and above & $489(86.9)$ & $74(13.1)$ & \\
\hline Economic activity & & & $<0.001$ \\
\hline Employed & $1,040(86.1)$ & $168(13.9)$ & \\
\hline Not-employed & $894(73.9)$ & $315(26.1)$ & \\
\hline Household Income & & & 0.282 \\
\hline Below 2 million KRW & $1,039(79.4)$ & $270(20.6)$ & \\
\hline Between 2 and 4 million KRW & $549(79.9)$ & $138(20.1)$ & \\
\hline 4 million KRW or above & $336(83.0)$ & $69(17.0)$ & \\
\hline Spouse & & & $<0.001$ \\
\hline Cohabitation & $1,397(81.2)$ & $324(18.8)$ & \\
\hline Separation & $251(67.7)$ & $120(32.3)$ & \\
\hline Bereavement & $284(88.2)$ & $38(11.8)$ & \\
\hline Drinking frequency & & & 0.710 \\
\hline Once a week or less & $1,547(79.9)$ & $389(20.1)$ & \\
\hline Once a week or more & $388(80.7)$ & $93(19.3)$ & \\
\hline Smoking & & & 0.179 \\
\hline Current smoker & $347(82.4)$ & $74(17.6)$ & \\
\hline Non-smoker & $1,590(79.5)$ & $409(20.5)$ & \\
\hline Subjective health status & & & 0.003 \\
\hline Good & $549(82.3)$ & $118(17.7)$ & \\
\hline Average & $700(83.4)$ & $139(16.6)$ & \\
\hline Poor & $728(79.6)$ & $186(20.4)$ & \\
\hline Walking per week & & & $<0.001$ \\
\hline One day or more & $1,367(82.7)$ & $286(17.3)$ & \\
\hline Less than one day & $569(74.3)$ & $197(25.7)$ & \\
\hline Depression & & & $<0.001$ \\
\hline Yes & $110(33.6)$ & $217(66.3)$ & \\
\hline No & $1,627(77.8)$ & $463(22.2)$ & \\
\hline $\begin{array}{l}\text { Disease or accident experience in } \\
\text { the past two weeks }\end{array}$ & & & 0.011 \\
\hline Yes & $304(70.5)$ & $127(29.5)$ & \\
\hline No & $1,573(79.1)$ & $416(20.9)$ & \\
\hline Frequency of meeting a neighbor & & & 0.001 \\
\hline Less than once a month & $426(64.8)$ & $231(35.2)$ & \\
\hline Twice or more per month & $1,440(82.3)$ & 309 (17.7) & \\
\hline Frequency of meeting a relative & & & 0.001 \\
\hline Less than once a month & $301(62.8)$ & $178(37.2)$ & \\
\hline Twice or more per month & $1,654(85.3)$ & $284(14.7)$ & \\
\hline
\end{tabular}


TABLE. III. VALUES OF FUNCTION WeIGHTS

\begin{tabular}{|c|c|}
\hline \multicolumn{2}{|l|}{ Age } \\
\hline $65-74$ & .011 \\
\hline $75+$ & -.032 \\
\hline \multicolumn{2}{|l|}{ Gender } \\
\hline Male & -.019 \\
\hline Female & .005 \\
\hline \multicolumn{2}{|l|}{ Education } \\
\hline $\begin{array}{l}\text { Elementary school graduation and } \\
\text { below }\end{array}$ & -.030 \\
\hline Middle school graduation & -.028 \\
\hline High school graduation & .003 \\
\hline College graduation and above & .007 \\
\hline \multicolumn{2}{|l|}{ Economic activity } \\
\hline Employed & .025 \\
\hline Not-employed & -.033 \\
\hline \multicolumn{2}{|l|}{ Household Income } \\
\hline Below 2 million KRW & -.007 \\
\hline Between 2 and 4 million KRW & -.007 \\
\hline 4 million KRW or above & .005 \\
\hline \multicolumn{2}{|l|}{ Spouse } \\
\hline Cohabitation & .017 \\
\hline Separation & -.027 \\
\hline Bereavement & .019 \\
\hline \multicolumn{2}{|l|}{ Drinking frequency } \\
\hline Once a week or less & .030 \\
\hline Once a week or more & .028 \\
\hline \multicolumn{2}{|l|}{ Smoking } \\
\hline Current smoker & .007 \\
\hline Non-smoker & .009 \\
\hline \multicolumn{2}{|l|}{ Subjective health status } \\
\hline Good & .007 \\
\hline Average & .004 \\
\hline Poor & -.011 \\
\hline \multicolumn{2}{|l|}{ Walking per week } \\
\hline One day or more & .020 \\
\hline Less than one day & -.034 \\
\hline \multicolumn{2}{|l|}{ Depression } \\
\hline Yes & -.037 \\
\hline No & .018 \\
\hline \multicolumn{2}{|l|}{$\begin{array}{l}\text { Disease or accident experience in the } \\
\text { past two weeks }\end{array}$} \\
\hline Yes & -.023 \\
\hline No & .015 \\
\hline \multicolumn{2}{|l|}{ Frequency of meeting a neighbor } \\
\hline Less than once a month & -.038 \\
\hline Twice or more per month & .015 \\
\hline \multicolumn{2}{|l|}{ Frequency of meeting a relative } \\
\hline Less than once a month & -.031 \\
\hline Twice or more per month & .018 \\
\hline \multicolumn{2}{|l|}{ Number of support vectors: 625} \\
\hline
\end{tabular}

TABLE. IV. The ACCURACY OF PREDicting THE SATISFACTION OF LifE ACCORDING TO THE CLASSIFICATION ALGORITHM OF THE SVM, \%

\begin{tabular}{|l|l|l|l|l|}
\hline \multirow{2}{*}{$\begin{array}{l}\text { Type of } \\
\text { SVM }\end{array}$} & \multicolumn{3}{|l|}{ Type of Kernel } \\
\cline { 2 - 5 } & Linear & Polynomial, & Gaussian & Sigmoid \\
\hline C-SVM & 91.25 & 90.58 & 92.63 & 89.88 \\
\hline Nu-SVM & 91.14 & 90.77 & 92.10 & 88.85 \\
\hline
\end{tabular}

\section{DISCUSSION}

This study developed an SVM-based model for predicting the satisfaction of life in old age using the data of the Seoul Statistics Survey. It was found that $20 \%$ of the surveyed elderly were dissatisfied with their current lives. "The Satisfaction of Life of Elderly Population Groups [27]" published by Statistics Korea in 2018 showed that the satisfaction of life ( $\geqslant 50$ years old) of South Korean was 5.4 out of 11 points, which was 1 point lower than the average of OECD countries (6.4 points), even though it compared with cannot be directly the results of this study. It was ranked as 28thamong35OEC Dmembercountries:2pointslowerthanDenmark (7.6 points; the top score), and even lower than Japan (5.8 points) [27]. If South Korean enters a post-aged society with continuing this trend, it is more likely to decrease the quality of life in old age. Therefore, it is necessary to prepare polices at a society level and take active measures to improve the quality of life in old age.

The results of this study revealed that health status (e.g., subjective health status, depression, and the experience of a disease or accident in the past two weeks), health habits (number of walking per week), and social network/ communication frequency (the frequency of meeting a neighbor and the frequency of meeting a relative) were main factors for predicting the quality of life in old age in addition to demographic factors (e.g., age, gender, education, economic activity, and marital status). Numerous previous studies evaluating the quality of life in old age reported that health status [30] and marital status [31] were main factors affecting the quality of life and these results, in addition to sociodemographic characteristics such as economic level [28] and age [29], agree with the results of this study. Previous studies on the satisfaction of life related to the economic stability of the elderly $[32,33]$ showed that those with low incomes generally were recipients of national basic livelihood guarantees and they were not satisfied with their living conditions when they did not have a spouse. As of 2018, the poverty rate of the elderly ( $\geqslant 65$ years) in South Korea was $48.8 \%$, which is four-folds of the average $(12.1 \%)$ of OECD countries [27]. Therefore, economic support is needed to improve the quality of life in old age.

Previous studies [32, 33, 34, 35] indicated that the better health status of the elderly increased the level of their life satisfaction while functional impairment (e.g., communication problem) that adversely influenced the interaction with others negatively affected the satisfaction of life. In particular, it was found that health status had a greater effect on declining life satisfaction in female elderly than male elderly and older elderly than younger elderly [33]. Additionally, many studies showed that marital status was a major factor affecting the 
quality of life [34]. The elderly living with spouses had a higher level of life satisfaction than those who were unmarried or those who lose their spouses [35]. Particularly, marital status was a very important factor in determining life satisfaction for older elderly than younger elderly.

An interesting finding of this study was that social networks and communication frequency were major predictors for the quality of life in old age. Kim et al. [36] also reported that the satisfaction of life increased with more frequent contacts and higher quality contacts with family members, friends, and neighbors (so-called better social networks). It could be because the elderly would require more social support than younger people in order to relieve loneliness and physical unwellness [36]. It is particularly well known that emotional support from the family has an important effect on resolving the loneliness of the elderly [16]. It has been reported that the elderly who receive more support from the family have better emotional health, better life satisfaction, and lower loneliness [36]. Therefore, in order to improve the quality of life in old age, it is necessary to establish a system that can increase the frequency of regular contacts (communication) with the members of local community groups such as volunteers as well as relatives, friends, and neighbors.

Another major finding of this study was that the prediction accuracy of C-SVM's Gaussian kernel was higher than that of linear kernel, polynomial kernel, and sigmoid kernel algorithms. The performance of nonlinear SVM depends on the kernel functions applied to the algorithms and parameters composing them. The Gaussian kernel is an algorithm that maps the data to a characteristic space of infinite dimension. Author in [21] also proved that it is an algorithm with high prediction accuracy. Therefore, it is believed that using a Gaussian kernel based C-SVM algorithm will be more effective for subsequent studies to develop models for predicting binary variables than using a sigmoid algorithm.

The results of this study would provide an important basis that must be considered for developing health policies for successful aging. Based on the prediction model of this study, it is needed to manage local communities systematically to enhance the quality of life in old age.

\section{REFERENCES}

[1] Statistics Korea, statistics of elderly persons, Statistics Korea, Daejeon, 2018.

[2] A. Bowling, Ageing well: Quality of life in old age, McGraw-Hill Education, London, 2005.

[3] P. H. Chen, J. S. Golub, E. R. Hapner, and M. M. Johns, Prevalence of perceived dysphagia and quality-of-life impairment in a geriatric population. Dysphagia, vol. 24, no. 1, pp. 1-6, 2009.

[4] R. Manrique-Huarte, D. Calavia, A. H. Irujo, L. Girón, and M. Manrique-Rodríguez, Treatment for hearing loss among the elderly: auditory outcomes and impact on quality of life. Audiology and Neurotology, vol.21(Suppl. 1), pp. 29-35, 2016.

[5] M. Pigliautile, F. Chiesi, C. Primi, S. Inglese, D. Mari, D. Simoni, E. Mossello, and P.Mecocci,Validation study of the Italian version of Communication Activities of the Daily Living (CADL2) as an ecologic cognitive assessment measure in older subjects.NeurologicalSciences,epub:doi.org/10.1007/s10072-019-03937-w, 2019.

[6] P. H. Noël, J. W. Williams, J. Unützer, J. Worchel, S. Lee, J. Cornell, W. Katon, L.H.Harpole, and E.Hunkeler, Depressionand comorbid illnessin elderly primary carepatients: impacton multiple domains of health status and well-being. The Annals of Family Medicine, vol.2, no.6, pp.555-562, 2004.

[7] J. B. Unger, G. McAvay, M. L. Bruce, L. Berkman, and T. Seeman, Variation in the impact of social network characteristics on physical functioning in elderly persons: MacArthur Studies of Successful Aging. The Journals of Gerontology Series B: Psychological Sciences and Social Sciences, vol. 54, no. 5, pp. S245-S251, 1999.

[8] E. Diener, R. E. Lucas, and S. Oishi, Subjective well-being: The science of happiness and life satisfaction. Handbook of positive psychology, vol. 2, pp. 63-73, 2002.

[9] U. Schimmack, P. Radhakrishnan, S. Oishi, V. Dzokoto, and S. Ahadi, Culture, personality, and subjective well-being: Integrating process models of life satisfaction. Journal of personality and social psychology, vol. 82, no. 4, 582-593, 2002.

[10] J. Butler, and J. Ciarrochi, Psychological acceptance and quality of life in the elderly. Quality of life Research, vol. 16, no.4, pp. 607-615, 2007.

[11] S. Y. Park, A study on depression, ADL, IADL, and QOL among community-dwelling, low income elderly. Journal of Korean Public Health Nursing, vol. 23, no. 1, pp. 78-90, 2009.

[12] A. Öztürk, T. T. Şimşek, E. T. Yümin, M. Sertel, and M. Yümin, The relationship between physical, functional capacity and quality of life (QoL) among elderly people with a chronic disease. Archives of Gerontology and Geriatrics, vol. 53, no. 3, pp. 278-283, 2011.

[13] T. Wada, M. Ishine, T. Sakagami, K. Okumiya, M. Fujisawa, S Murakami K Otsuka S Yann $T$ Kita and $K$ Matsuhavachi Depression in Japanese community-dwelling elderly-prevalence and association with ADL and QOL. Archives of Gerontology and Geriatrics, vol. 39, no.1, pp, 15-23, 2004.

[14] H. Byeon, Developing a model to predict the social activity participation of the senior citizens living in South Korea by combining artificial neural network and quest algorithm. International Journal of Engineering \& Technology, vol. 8, no. 1.4, pp. 214-221, 2019.

[15] A. P. Lane, C. H. Wong, Š. Močnik, S. Song, and B. Yuen, Association of Neighborhood Social Capital With Quality of Life Among Older People in Singapore. Journal of Aging and Health, vol. e-pub: doi.org/10.1177/0898264319857990, 2019.

[16] O. M. R. Gouveia, A. D. Matos, and M. J. Schouten, Social networks and quality of life of elderly persons: a review and critical analysis of literature. Revista Brasileira de Geriatria e Gerontologia, vol. 19, no. 6, pp. 1030-1040, 2016.

[17] H. Byeon, and S. Kim, Development of risk prediction model for stroke among Korean older adults using quest algorithm: a community-based cross-sectional study. International Journal of Applied Engineering Research, vol. 10, no. 79, pp. 93-96, 2015.

[18] S. G. Kumar, A. Majumdar, and G. P, Quality of life (QOL) and its associated factors using WHOQOL-BREF among elderly in urban Puducherry, India. Journal of clinical and diagnostic research: JCDR, vol. 8, no. 1, pp. 54-57, 2014.

[19] J. Butler, and J. Ciarrochi, Psychological acceptance and quality of life in the elderly. Quality of life Research, vol. 16, no. 4, pp. 607-615, 2007.

[20] S. Khan, and T. Yairi, A review on the application of deep learning in system health management. Mechanical Systems and Signal Processing, vol. 107, pp. 241-265, 2018.

[21] H. Byeon, Model development for predicting the occurrence of benign laryngeal lesions using support vector machine: focusing on South Korean adults living in local communities. International Journal of Advanced Computer Science and Applications, vol. 9, no.10, pp. 222227, 2018.

[22] J. Chorowski, J. Wang, and J. M. Zurada, Review and performance comparison of SVM-and ELM-based classifiers. Neurocomputing, vol. 128, pp. 507-516, 2014.

[23] Y. C. Wu, Y. S. Lee, and J. C. Yang, Robust and efficient multiclass SVM models for phrase pattern recognition. Pattern recognition, vol. 41, no. 9, pp. 2874-2889, 2008.

[24] N. Herrmann, N. Mittmann, I. L. Silver, K. I. Shulman, U. A. Busto, N. H. Shear, and C. A. Naranjo, A validation study of the Geriatric Depression Scale short form. International Journal of Geriatric Psychiatry, vol. 11, no. 5, pp. 457-460, 1996. 
[25] B. Scholkopf, and A. J. Smola, Learning with kernels: support vector machines, regularization, optimization, and beyond. MIT press, Cambridge, 2001.

[26] Available:https://ratsgo.github.io/machine\%20learning/2017/05/29/SV M2/

[27] Statistics Korea, Basic Research on Life Satisfaction of the Elderly, Statistics Korea, Daejeon, 2018.

[28] M. H. Alshamali, M. M. Makhlouf, M. Rady, A. Selim, N. Abdel, S Ismail, and M. Fawaz, Quality of life and its predictors among Qatari elderly attending primary health care centers in Qatar. Middle East Journal of Family Medicine, vol. 7, no. 10, pp. 9-19, 2019.

[29] K. H. Jo, and H. J. Lee, Factors related to life satisfaction in young-old, old, and oldest-old women. Journal of Korean Academy of Nursing, vol. 39, no. 1, pp. 21-32, 2009.

[30] C. W. Han, E. J. Lee, T. Iwaya, H. Kataoka, and M. Kohzuki, Development of the Korean version of Short-Form 36-Item Health Survey: health related QOL of healthy elderly people and elderly patients in Korea. The Tohoku journal of experimental medicine, vol. 203, no. 3, pp. 189-194, 2004.
[31] T. Rakhshani, D. Shojaiezadeh, K. B. Lankarani, F. Rakhshani, M. H. Kaveh, and N. Zare, The association of health-promoting lifestyle with quality of life among the Iranian elderly. Iranian Red Crescent Medical Journal, vol. 16, no. 9, e-pub: doi.10.5812/ircmj.184042014.

[32] Y. S. Kim, and K. H. Suh, Living arrangement, satisfaction with living, end depression among the Korean elderly. Korean Journal of Gerontological Social Welfare, vol. 18, no. 1, pp. 273-290, 2002.

[33] J. D. Kwon, and J. Y. Cho, A study of factors influencing the life satisfaction of the aged. Journal of the Korea Gerontological Society, vol. 20, no. 3, pp. 61-76. 2000.

[34] H. R. Hedayati, N. Hadi, L. Mostafavi, A. Akbarzadeh, and A. Montazeri, Quality of life among nursing home residents compared with the elderly at home. Shiraz E-Medical Journal, vol. 15, no. 4, e-pub: doi.10.17795/semj22718, 2014.

[35] M. Tajvar, M. Arab, and A. Montazeri, Determinants of health-related quality of life in elderly in Tehran, Iran. BMC public health, vol. 8, no. 1, e-pub: doi.org/10.1186/1471-2458-8-323, 2008.

[36] H. K. Kim, M. Hisata, I. Kai, and S. K. Lee, Social support exchange and quality of life among the Korean elderly. Journal of Cross-Cultural Gerontology, vol. 15, no. 4, pp. 331-347, 2000. 